\title{
Running the Gauntlet: Understanding Commercial Sexual Exploitation and the Pathways Perspective to Female Offending
}

\author{
Lisa Pasko ${ }^{1} \cdot$ Meda Chesney-Lind ${ }^{2}$
}

Received: 31 January 2016 / Revised: 11 August 2016 / Accepted: 16 August 2016 /

Published online: 31 August 2016

(C) Springer International Publishing AG 2016

\begin{abstract}
Purpose Although there exists a growing body of research on female delinquents, few studies have investigated extensively the life courses of young women with histories of commercial sexual exploitation (CSE). Adding to the pathways perspective to offending literature, this article examines the narratives of young women with histories of CSE, emphasizes what they interpret as turning points, and illustrates their criminal trajectories as a "gauntlet."

Methods This article presents a case study of six female offenders with histories of commercial sexual exploitation.

Results Interviewees identified disrupted relationships with their mothers, early experiences of sexual abuse, and justice involvement as turning points toward their "gauntlet" of CSE and criminality. In addition, intergenerational normalization of drug abuse and violence in their homes, economic and racial marginalization, and absence of nurturing relationships led to interviewees' interpretations of their lives as limited in agency, freedom, and change and filled with criticism, constriction, and punishment. Such interpretations preceded their return to offending behaviors.

Conclusions The pathways perspective to understanding sexually exploited female offenders is an important contribution in the field of feminist criminology. When combined with understanding young women's turning points toward delinquency and CSE and their perceived effect of system involvement, the pathways perspective
\end{abstract}

Lisa Pasko

Lisa.Pasko@du.edu

Meda Chesney-Lind

meda@hawaii.edu

1 Department of Sociology and Criminology, University of Denver, 2000 E. Asbury Ave SH 441, Denver, CO 80208, USA

2 Women's Studies Program, University of Hawaii at Manoa, 2424 Maile Way, Saunders Hall, Room 722, Honolulu, HI 96822, USA 
underscores the constraint and challenges these young women express as they navigate their communities, approach relationships, and return to criminality.

Keywords Female delinquents Pathways perspective Commercial sexual exploitation - Sex trafficking $\cdot$ Sexual abuse

\section{Introduction}

In recent decades, the commercial sexual exploitation (CSE) of children has emerged as a significant problem on the national, regional, and international arenas. The CSE of children is defined as any sexual conduct or live, filmed, or photographed sexual performance a youth (aged 17 and younger) engages in, is solicited to, or is forced to perform in return for money, food, drugs, shelter, clothing, gifts, or other goods. The extent of CSE is unknown in the USA, although the estimated number of youth at risk ranges between 100,000 and 300,000 annually [30].

For girls, the pathways toward CSE appear to be multi-faceted and complex, entailing different relationships, many layers of enthrallment, socialization to these behaviors beginning in early adolescence, criminalized survival and coping strategies, and varying degrees of family court and justice system intervention [46]. Often, the dynamics of their family lives involve growing up in severely distressed and marginalized households, where lack of adequate employment, drug abuse, sexual exploitation, and violence are normalized [12]. Using a case study of six female offenders with histories of CSE, this article examines their narratives and underscores their interpretations and reflections of their life courses. Additionally, it expands the pathways perspective to crime by further understanding these young women's in-depth accounts of turning points, marginalization, victimization, and continuation of criminal trajectories. For justice-involved young women with CSE histories, the journey down their pathways into and out of criminal activity and deepening court and correctional involvement resemble running a "gauntlet" - a constricting and punishing attack coming from all sides. Lastly, this article concludes with implications for research of female offenders with CSE histories and for gender-responsive policies and practices when responding to this population.

\section{Pathways Perspective and Girls' Delinquency}

Traditional research on crime and delinquency has long been criticized for its failure to adequately represent, incorporate, and understand female offenders [4, 8, 10]. Using different methodological and theoretical approaches to understanding the etiology behind crime trajectories, the pathways perspective to crime examines which life experiences, particularly childhood ones, place one at risk of offending. Such research indicates that sexual, emotional, and physical abuse - particularly sexual trauma - as well as other forms of childhood strain (family disruption, substance-dependent and/or criminally involved parents, neglect) are defining features in the lives of many female offenders, and it is often related to one's likelihood of committing crimes ([1]; Author 2013, 2010; [4, 6, 9, 10, 16, 21-23, 27, 34-36, 37, 47]). These experiences often precipitate running away (their escape strategy) and increase exposure to criminal 
opportunities, recruitment by older men and/or gang members into sex trafficking, and sexual victimization on the streets (Author 2013; [8, 11, 24, 46]). Moreover, the consolidation of poverty, racial marginalization, limited job opportunities, escape from violence in the home, volatile relationships, and prior sexual abuse often pilot girls toward criminality, such as prostitution (see [6, 14, 18, 24, 34, 46, 48]).

In particular, sexual abuse affects girls' ability to form attachment bonds needed to deter delinquency and anti-social behavior. It increases the likelihood of depression, suicide attempts, traumatic sexualization, problematic substance use, self-injury, violence, eating disorders, delinquent peer groups, risky lifestyles, feelings of powerlessness, and difficulties in maintaining employment ([1]; Author 2010; [3, 5, 15, 25, 26, 29, 41, 44]). Having low self-worth and gender hatred, sexually abused girls often blame their mothers, do not trust other girls, and find themselves more comfortable and confident with boys, sometimes leading to competition and violence with other girls ([1, 2]; Chesney-Lind \& Pasko, 2013; [8]).

Furthermore, early childhood sexual abuse establishes the foundation for future sexual exploitation through the development of feelings of stigmatization, chronic shame, guilt, and betrayal $[15,20,48]$. The profound disruption in psycho-social functioning that results from sexual trauma creates difficulties in regulating impulses, somatic distress, and problems with developing emotional attachment to non-abusive relationships while fostering familiarity and comfort with sexually exploitative ones; it can create the feeling of being in an inescable gauntlet [47]. Connected to family disruption, trauma, and abuse are developmental deficits, school failure, and high prevalence rates of co-existing mental health and substance abuse disorders, particularly for persistent offenders and those exposed to CSE [27, 32, 42, 43].

Using these details about girls and women in trouble with the law, numerous scholars have made significant contributions in feminist criminology through their pathways theoretical developments (see [45]). Based on the constructed life histories of 80 men and women felony offenders, Daly [10], in her seminal work, identified five prototypical pathways: street women - escape and survival, involving women fleeing abuse and engaging in survival strategies such as prostitution, theft, and drugs; drugconnected women, describing the use and trafficking of drugs by women in concert with romantic partners/family; harmed and harming women, involving offenders who have experienced traumatic abuse which led to their chronic criminality and violence; battered women, categorizing women whose crime is directly linked to their extreme victimization by their romantic partners; and other, entailing women whose crimes were economic-motivated. Building on such typologies, other pathways scholars have also specified similar trajectories and characterized them according to childhood victimization [6], abusive homes and gender oppression [13], extreme economic and racial marginalization [34, 35], normal-functioning with drug-dependence [7, 19, 40], adult relationship dysfunction [37], socialized subculture, and anti-social aggression, resulting from extensive experiences of deprivation, trauma, hostility, and relationship issues [7].

Based on such tradition, this article further interrogates how victimization and extreme marginalization affect girls' pathways to delinquency, CSE, and other forms of criminality and violence. Demonstrating how many of these typologies overlap in their lives, it shows how for girls who experience a combination of severely disrupted families, drug abuse, trauma, violence, abandonment, sexual exploitation, and early 
system involvement, their pathways into and out of the justice system can be understood as that of a gauntlet. Building off previous work that also utilizes this metaphor [48], this article places CSE girls' key life events, experiences, and reflections within their economic and racial contexts, as it examines their interpretations of significant relationships, turning points, and personal agency - their capability to exert control over the interactions, events, and outcomes in which they are enmeshed (see [39]). It reveals an additional and alternative understanding of CSE girls not currently found in the literature, with a particular focus on their relationships with their mothers. The following questions guide the case study: What life course experiences and events precipitate young women's entrance into and continuation of CSE and offending? How do they discuss and interpret such experiences, and when considering their life histories, what events do these young women consider as turning points?

\section{Method}

The data represent a case study derived from a larger project that focused on the lives and correctional involvement of girl offenders; it was performed across eight different jurisdictions in the USA, from 2008 to 2012. This article centers on the narratives of six female offenders who discussed their pathways toward criminality and their life course experiences with CSE. We use these six cases together in order to examine in-depth and with detail various themes and processes emerging from them (see [33], p. 169). Overall, the sample was gathered through referrals from justice professionals the first author made in the community. These professionals and program staff were essential in referring girls to be interviewed, in helping to secure safe and private places where the girls felt comfortable completing such interviews, and in keeping as an additional contact for the girls, in order to facilitate their return for future conversations.

So as to gather participants' interpretations of their experiences and expressions of their life narratives and in order to attenuate preconceived notions about girl offenders' lives, repeat intensive interviewing with a broad, open-ended instrument was the method chosen. Repeat, intensive interviewing also allowed multiple opportunities for discussion about topics that one may often guard and conceal, such as gang involvement, sexual abuse, drug use, and commercial sexual exploitation. Each of the six participants was interviewed three times, 5 to 7 months apart. The first conversation was used chiefly to develop rapport with the interviewee, to ameliorate concerns about judgment that they feared might arise in the interviews, to alleviate trepidation, and to create trust and comfort in thinking and talking about life experiences. Each initial interview took place in a private setting, arranged in concert with the first author and her research assistant, and lasted between 60 and $90 \mathrm{~min}$.

Likewise, employing an interview guide of loosely structured topics, the subsequent second and third interviews of the participants were performed to gather more detail, create more depth to their thoughts and feelings about their narratives, return to themes that had earlier emerged, chart new experiences and progression in their lives, and offer each participant a well-developed sense of appreciation, understanding, and affirmation. Girls were asked open-ended inquiries into 
interpretations of their significant childhood to contemporary experiences, prompted intermittently to discuss family structures and relationships, neighborhood and community dynamics, school participation, significant relationships, sexual behavior, drug use, and social/justice system involvement. This multiple interviewing technique allowed for opportunities to study the data and return to the participant with additional queries that would add to analysis and to the depth of their narratives. It also gave interviewees time to be reflexive in their recollections and interpretations. The second and third interviews lasted between 2 and $3 \mathrm{~h}$ each; altogether, nearly $35 \mathrm{~h}$ of interview data were analyzed. Institutional Review Board approval was given for all interviews performed in this study.

Extensive notes were taken during the interview and all interviews were taped as well, both recorded and transcribed within $72 \mathrm{~h}$ by the first author or her research assistant. The interviewees chose their own pseudonyms, and these names were used in all notes and transcripts. The first author and her research assistant worked independently in their coding to ensure incisive thematic analysis, meeting bi-weekly to review notes, read through transcripts, and compare codes. Presented as a case study of female offenders with CSE histories, we use analysis of specific details to develop a profound portrait and exploration of the offenders' life courses and turning points, showing how patterns of extreme marginalization, violence, drugs, and sexual exploitation arise within each trajectory.

Despite the ability of a case study to delve deeply and intensely into subject material, the sample size of six offenders does present limitation-mainly the ability to generalize theoretically about pathways perspective and to generalize about other CSE-involved youth or court-involved girls. The events, relationships, turning points, and interpretations offered in this case study may not necessarily be applied to the larger population. However, case studies have been deemed important in feminist scholarship as a way for looking for specificity, exceptions, and completeness (see [33], p. 174). Individual case histories and intensive interviews with a small number of participants have also been the method of several notable criminological works (for example, [12, 17, 28, 38]). Indeed, in Daly's work, three of her five pathways typologies included six or fewer women (battered women, drug-connected women, and economic-motivated/ other). Key summary information on the subjects, including age (at first interview), race, system involvement, and age at CSE, are presented in Table 1. Thematic analyses as well as excerpts that explicate interviewees' interpretations of such themes are reported in the next section.

\section{Findings}

This section presents the findings from the interviews divided into two sections. First, comporting with the literature on gender and delinquency and the pathways perspective, this section describes their life course histories, including childhood experiences, family backgrounds, victimization, encounters with alcohol and substance abuse, racial and economic marginalization, school experiences, relationships and romantic attachments, and justice involvement. Second, themes emerging from girls' interpretations of their life narratives, personal agency, and moments perceived as turning points are included. 
Table 1 Summary background of girls

\begin{tabular}{|c|c|c|c|c|c|c|c|}
\hline Interviewee & Race & Age & $\begin{array}{l}\text { Child protective } \\
\text { services } \\
\text { involvement }\end{array}$ & $\begin{array}{l}\text { Age of } \\
\text { first } \\
\text { arrest }\end{array}$ & $\begin{array}{l}\text { Age of } \\
\text { CSE } \\
\text { onset }\end{array}$ & $\begin{array}{l}\text { Number of detentions, } \\
\text { commitments and/or im- } \\
\text { prisonments }\end{array}$ & $\begin{array}{l}\text { Status at last } \\
\text { interview }\end{array}$ \\
\hline Deirdre & Black & 22 & Yes, age 5 & 12 & 4 & 5 & $\begin{array}{l}\text { Homeless, on } \\
\text { parole }\end{array}$ \\
\hline Lucky & Black & 19 & Yes, age 11 & 14 & 12 & 2 & $\begin{array}{l}\text { Lives with } \\
\text { boyfriend, } \\
\text { on parole }\end{array}$ \\
\hline Bella & Latina & 18 & No & 15 & 13 & 0 & $\begin{array}{l}\text { Lives with } \\
\text { boyfriend, } \\
\text { on probation }\end{array}$ \\
\hline Sunshine & White & 18 & Yes, age 8 & 14 & 8 & 1 & $\begin{array}{l}\text { Lives with } \\
\text { mother, on } \\
\text { probation }\end{array}$ \\
\hline Sierra & Latina & 18 & Yes, age 6 & 12 & 12 & 1 & $\begin{array}{l}\text { Lives with } \\
\text { brother, on } \\
\text { probation }\end{array}$ \\
\hline Charity & White & 19 & Yes, age 11 & 13 & 10 & 1 & $\begin{array}{l}\text { Lives with } \\
\text { boyfriend, } \\
\text { on probation }\end{array}$ \\
\hline
\end{tabular}

\section{Life Histories}

The presence of residential instability, poverty, family arrest and incarceration records, fighting, drugs, and physical violence in the home was strong memories for all of the interviewees. The disruption and instability in the house often led to feelings of loneliness, neglect, and fear. For example, Charity's early memories of her household were filled with chronic stress, neglect, violence, and drug use. An only child, Charity, moved residences frequently, sometimes residing in weekly rented motels, where her mother and mother's boyfriend engaged in trafficking of prescription pills and prostitution. Charity explained, "Mostly what I remember is packing my bag all the time and moving a lot. We were always living with some guy my mom met or on someone's couch or then the motel. But always some guy who'd, you know, treat her like a like crap. It wasn't like she ever like hit me or anything. Just never...I don't know, like, wanted me around, you know? Like I felt like that. But when I got older, I think I was her best friend because she'd....like confide in me. I felt like I had to fix things for her or try and make her life better. Yeah, she was young and she also... you know...was in it. That life. Lots of, like boyfriends, and her thing was pills and so I was just sort of there sometimes because she was so out of it." At age 7, when her mother was passed out, her mother's boyfriend at the time molested Charity. Blaming her mother for not intervening, Charity explained: "My mom was out of it a lot and there would be guys around and I always felt scared. When she was around, she was really, you know, like messed up, like a zombie sometimes, laying around a lot or something. I'd have to leave for a while a lot of the time, and was scared a lot and my stomach would hurt, which someone told me later was because I was hungry and not getting enough food." 
Through Craigslist's (online site for commercial and personal advertisements), her mother's boyfriend began the sexual exploitation of Charity when she was 10; a year later, he and her mother were arrested, and Charity was placed into foster care by Department of Health and Human Services (DHHS, responsible for child protection and family welfare services). Charity identified this moment as a turning point in her life: "You'd think this would be a good thing? But it wasn't. I was not good. I am not sure I knew it then, but maybe I did. I knew I'd never see my mother again. And I haven't, and that has been it. You know. I don't hate her. I just...it's my mother." Indeed, Charity identified her relationship with her mother as a relentless source of anxiety, stress, disappointment, and rejection, and yet, when the relationship was truncated, Charity felt responsible and abandoned, with a turn toward more criminality. While in foster care, she struggled with alcohol use and with "anger issues" and was arrested on sexual abuse charges on her younger foster brother: "It was stupid, I know. I was still so stressed and alone and so yeah, there's this kid and the next thing I know we're doing this with each other. I know I am responsible and I wanted to be mean to him and I am telling [case worker] what happened and I get arrested."

Charity completed 9 months in a youth correctional facility before entering a therapeutic group home for children, with three foster care placements to follow. Expressing that her arrest and subsequent registration as a sex offender were pivotal in her life, Charity, pregnant at 17 , continued on probation for shoplifting and drug charges at the time of our last interview: "It's been hard to get things done. Because of my offense, I am not eligible for, like, college loans, and I cannot live in [subsidized housing] or get assistance like that. So I leave [son] with my boyfriend at night and work at [strip club]. I make good money. I'm good at it. You know, it's...kinda like ummm...normal."

Likewise, Lucky's early memories in her house were of moving frequently, of being afraid, of witnessing her mother being physically assaulted by her father and by other men who came into the home, and of watching adults - many of whom were strangers-buying and using various drugs and alcohol. As the oldest, Lucky was often left to take care of her three younger siblings: "You know, I do have memories of barbeques, and playing with cousins and my sisters, you know, it was OK. But it wasn't ok, you know? There was a lot of screaming and my mom cheated on my dad a bunch of times and he would get drunk and hit her and sometimes hit my brother, and there would always be these people around, when I was about 10 or 11 , I would just leave and got tired of it and needed a break. I mean like I am the one trying to make sure there was food and clean up shit and watched my brother and sisters and I was like, who is taking care of me, you know, like I am the kid, you know, I am the kid here, and who is taking care of me?"

At age 9, one of her father's friends began molesting her, contributing to her feelings of frustration and desires to escape. At age 11, after her parents were jailed on domestic violence, drugs, and weapons charges, Lucky and her siblings were placed with her grandmother, where she continued to run away and break curfew. Lucky attributed her parents' arrests and placement with her grandmother as ultimately leading her to her first romantic attachment who exploited her: "Do you know what it feels like to be dropped at grandma's and not know if she's coming back or what? That night.....Yeah, angry all the time, I didn't listen ....I started hanging out with [gang friend] — 'oh baby girl, you know, you're so pretty and c'mon do this' - and I wanted to be with them and 
run with them [gang] and so I started smoking pot and doing that [CSE] and then I know, like I was happy not to be around all my family drama and worry about my mom and stuff, but then, I wasn't happy, cause I'm like, does she care?" When she was 17 , Lucky assaulted her father with a weapon, an offense that led to detention. Her father would not press charges or cooperate with the investigation; Lucky was therefore not charged with attempted murder. Moving from her boyfriend's, friends', or mother's homes and, occasionally a motel or shelter, Lucky continued on probation after the age 18 on marijuana and theft charges. Despite her assault on her father and her role in the gang, the greatest source of stress for Lucky remained with her relationship with her mother. "I get her, but...that doesn't mean I didn't wish she was different too. Dad, he's gonna be a dick no matter what, but she could be different." Ultimately, Lucky blamed her mother for the chaos in the home and for her neglect. "It's her fault. She always started stuff and still does and makes it so I don't wanna be around her."

A self-described soft-spoken middle child with four siblings, Bella, also found that the caretaker role she assumed in her family to be overwhelming for her. "“II took care of a lot at home...I watched my [3 younger] brothers...my older sister was popular and not home and there was a lot of fighting between her and my dad a lot about it and I was just left to take care of everything. My dad liked that I helped out, and I like making him happy." Emigrating from Mexico, her father, undocumented until she was 10, worked two jobs and was absent from the home frequently. Bella's mother struggled with mental health issues that went untreated; her father wanted to keep the condition private since he "worried about attention it could bring to them. We don't want cops at our house." When her mother had an "episode," she would become physically abusive to Bella and her siblings or she would lock herself in her room, leaving Bella to miss school and care for her brothers. "My dad...he's always working and my mom and I....she has problems. She had a lot of problems. My dad would treat her like just do whatever she wants, right, because we just have to deal with her and, like, not upset her or anything. You know, my mom was so beautiful. My sister was like her. Everyone would always say, [sister] is just like my mom. But not me, and anyway....yeah, my mom, one day it would be all OK and happy and the next, I'd just want to get out." Reiterating how distant she felt from her mother, Bella described how this led to her attachment to her boyfriend: "My mom is beautiful. ....there was one day when she got me this dress and did my hair and I did feel like her.....but...I'm the ugly one. Sometimes I'd just get ignored....but then sometimes...I was the ugly one. But not to (boyfriend). He was not like that."

Having trouble making friends and almost failing her course work at school due to absences, Bella began intentionally skipping classes at age 13. After one of her mother's abusive "episodes," Bella, feeling hungry and unkempt, chose to skip school and instead go to a convenience store by her house. This is where she met her current "boyfriend"- - a gang-involved man 10 years her senior - thus beginning her CSE. At the time of the last interview, she was finishing probation for theft charges and living with this boyfriend, intimating that gang involvement and prostitution continued in her life. Bella expressed that change was not possible for her right now and that was "ok since I'm almost off probation and things are good with [boyfriend]. I think he loves me. I think my dad hopes I will marry him because then you know, like it's I'm doing okay then, getting married, having kids, being a mom, that's all like normal, you 
know?" Bella ended by stressing her relationship with her mother continued to be disrupted" "My mom does not think of me at all, I'm sure."

Deirdre's memories of her childhood before the age of nine seem vague to her, with most of her background conveyed to her by social workers, her foster mother, and probation officers. Homeless and without extended family and other forms of social support, Deirdre's mother, a prostitute since the age of 14, would often beat her and leave her alone for long periods of time when she "was out turning tricks and partying and whatever." Police discovered Deirdre and her mother living under an overpass when she was 5 years old. A physical examination would show fresh and healing bruises on Deirdre's body, along with vaginal and anal trauma and a sexually transmitted infection. With her mother incarcerated and herself removed to foster care, Deirdre had difficulty maintaining relationships or understanding the behavioral and academic requirements of school. She spent much of her time alone and disconnected from other people. Her individualized education plan revealed developmental and psychological delays impeding social attachments at home and at school. "My foster mom used to tell me that I would just sit on the front lawn and have no idea how to play or what to do and then I would come in house and hit other kids or act in a way she, I don't know, just like I was alone. I did do special classes in school, reading and it was hard, you know what I mean? I do remember being alone a lot and feeling angry and maybe when I was about 10 or so, that's when I started drinking. I would go and hang out with these older kids up the street over at this apartment building and we would drink and smoke [pot]."

Placed on supervision at age 12 for shoplifting and truancy, at 13, Deirdre was hanging out at a local convenience store when three men approached her and convinced her to ride in their vehicle. Sustaining a prolonged gang rape, Deirdre explained how that was a critical moment in her life. Receiving no trauma-informed treatment, she began to use crack shortly afterwards in order "to get away from it" and prostituting to pay for it: "After that, I didn't really go to school and I was with these.... hanging around with [pimp] and he had drugs and that's when I started getting arrested a lot for being out, for the drugs too, and I yeah, um, I don't know, don't know..... how many times now [arrested for prostitution]." Dropping out of school at age 16, Deirdre had been in and out of detention, committed for 8 months to a juvenile correctional facility where she aged out at 18; she went to adult prison when she was 19 on crack cocaine charges. Upon release, she struggled with sobriety and was arrested for prostitution within 3 months. "I went to a homeless shelter when I got out. There are always men there like that [pimps]. I knew I'd find someone I could live with and then, you know, back in the life, but then I was in an apartment and not [shelter], and that was better." During the last interview, Deirdre was on parole and recently living in parks, under overpasses, or at her pimp's apartment, with her only "trustful" person in her life being her former foster mother. Expressing loneliness, lack of connections, and briefly explaining the death of her son (who died at age 9 months due to on-going complications from in utero trauma and drug addiction), Deirdre explained how the absence of a mother in her life was meaningful in her criminal pathway: "For me (pause), my mother started it all. I don't have a memory of her, I am her. I had [foster mother] and she has been there, even paid to bury my son. But she's had a lot of [foster] kids and I am just one. But she lets me use her address and phone number when I need something like that. And occasionally will give me some spaghetti, too." 
Sierra and Sunshine's early childhoods mimicked many of these stressors and fragmentations. Sierra's early childhood was marked by chronic unemployment and alcohol abuse by her father as he mother worked two jobs. Molested by her father starting at age 5, DHHS eventually removed her and her younger brother temporarily to foster care, and her father was subsequently arrested, convicted, and incarcerated for the sex offense against her. After "unhelpful" therapy ("I don't remember it dong anything for us.") and returning to her mother's home, Sierra began breaking curfew, smoking, drinking, and ditching school by age 11 . "When we went back to live with [her mother], I never listened to her. I hated her." She was arrested for shoplifting and placed on probation when she was 12 . At this time, Sierra began associating with a neighbor and former friend of her father's, who facilitated her CSE, first through sexual "favors" for trade (rides, alcohol, and food) then through the sale of her to his acquaintances. Despite a restraining order against him, Sierra ran away twice to find her father after his parole. Defensive of her father with blame placed on her mother, Sierra explains that her fragmented and volatile relationship with her mother has preceded most of her justice involvement and her CSE: "I mostly did it to piss off my mom and get things...I do blame my mom. I know she works a lot and I speak English and she doesn't really, so we don't talk much, but I just think if she were, I don't know, just did something different for me, I would be OK, it would be better. I just think that if she made different choices my life would be different and it's unfair to put it all on my dad." At the time of the last interview she was finishing probation for drug charges and living with her older half-brother and occasionally staying with her mother "until it starts up again." Feeling that her CSE was limited to her neighbor and she was no longer "doing that," Sierra also felt that she would rather return to live with him than endure "another nasty fight with [mother]."

Raised by a single mother who had a criminal record for forgery and struggled with addiction to prescription pain medication, Sunshine similarly found her childhood filled with constant stress: absent or intoxicated mother, constant fighting in the home, frequent moves, and sexual abuse by two of her mother's boyfriends. After her second experience with sexual assault, Sunshine began drinking and smoking marijuana, sometimes with her mother. Arrested on drug charges, her mother was incarcerated when Sunshine was 12, leaving her to live with various family members; she continued to drink alcohol and smoke marijuana. Reflecting on her mother's arrest which happened in front of her, Sunshine explained, "I think that was my saddest day. When they took her." Sunshine's initiation into CSE began with a man, twenty years her senior, whom she met online when she was 13 , followed by her arrests for marijuana, shoplifting, and credit card theft. "There was a lot of moving around, especially after mom went to jail. I live with my mom now that she's out and we fight sometimes, but I'm glad to be back with her because I worry about her. And yeah, when she was away, I missed her and was glad when she'd write or when I got to see her a few times. Because otherwise, I was just alone a lot at my aunt's and grandma's until I met [boyfriend]. Then I started to feel good, even though I didn't always like it."

\section{Interpretations and Reflections of Their Pathways}

When girls in the study reflected upon their pathway to offending and court and correctional involvement and thought about what their future lives might involve, they 
could not envision change, inferring that any deviation would be controlled by external sources, not internal mechanisms. While they had desire to improve the conditions of their lives, they felt their agenic power constrained by current correctional supervision, past choices and experiences, or both. For example, options to go to college (Charity) or work a minimum-wage job (Deirdre) seemed unattainable, while recognizing that avoiding trouble or re-arrest (Lucky, Sunshine) or thinking in a future-forward direction is difficult (Sierra, Bella):

"I have no idea where I will be. Probably jail. Just depends if I get caught again for something." - Lucky

"I'd like to work for McDonalds and live in a duplex, but that probably can't happen."-Deirdre

"I used to think about college or something...but I don't have control over that. Except for [son], I don't have a lot to say about a lot." -Charity

"I'll end up wherever I end up." -Sierra

"I hope it's not jail again. It's hard to stay out of trouble." -Sunshine

"It'd be good to go back home or go to school, but you just can't start over. No one really lets you do that, you know?" -Bella

In addition, girls' reflections of their life experiences contained emotional familiarity with continual crisis, lack of attachment to caring and nurturing sources, and sensitivity to criticism and to perceptions of being judged or disliked. With an absence of close confidantes and difficulty forming friendships with prosocial peers, especially with people outside of their families, girls were left feeling angry, isolated and alone:

"There were always people around, but I felt alone a lot." -Sunshine

"I don't remember having a lot of friends when I was younger. Pretty much just my brother and my mom after my dad went away." -Sierra

"When I think of being a kid, I just think how stressed I was. How everything was dirty and smelled, and I never knew where we were going to live or if I was going to school or what was going on. Just stressed. I remember when I was about maybe nine, like third grade maybe, right before we went to the motel, and I, like I was, I am going to explode. I don't know. Just couldn't take seeing my mom so unhappy all of the time, and moving, and worried."- Charity

"I get it [criticism] from all sides." -Lucky

For some, parents' arrests and incarceration were interpreted as turning points in their lives. However, their relationships with their mothers appeared especially 
problematic in their reflections, as girls varied between worrying about and taking care of their mothers to blaming their mothers for facilitating their CSE or failing to protect them from it. All of the young women in this case study discussed an event associated with their mothers as the turning point that either directly or indirectly led to their CSE as well as other criminality. Four of the girls described their strained relationships with their mothers and lack of nurture and care as contributing to pent-up hostility and eventual acts of aggression and violence (Charity, Lucky, Sierra, and Deirdre). Additionally, they animated the anger over what they perceived as their mothers' failures (mental health disorders, drug addictions, poor associations with men, infidelity, and criminal behaviors) while often excusing or accepting their fathers' absence, violence, and criminality. Especially apparent in the cases of Lucky and Bella, the decision to escape the household and be released from the pressure of being the primary caretaker led to meeting the perpetrator of their CSE, which became and remained a strong romantic and intimate attachment. Overall, interviewees expressed a longing for a connection to their mothers devoid of intoxication, violence, and abuse:

"If my mom could have been more independent, then things would be different." - Sierra

"Even when your mom is like my mom, you know, with drugs, and boyfriends, and all of that what happened, I still worry about her and wish it was different and wonder and I don't even really know where she is."- Charity

"I am like my real mom. I guess I am just like her. There's no.....um...I don’t think I can change that." -Deirdre

"Of course I love my mother. People say I am just like her and I don't take that in a bad way even though we fight."-Sunshine

These negative emotional experiences, complications with relationships closest to them, and absence of friendships with other girls compounded the psycho-social effects of early sexual abuse and situated them for a comfort, enthrallment, and familiarity with CSE. Part of that enthrallment entailed feelings of romantic attachment to the source, denial of CSE existence, and increased senses of worth and power, however temporary:

"I did feel pretty, like my mother. [Boyfriend] chose me and wanted to marry me." -Bella

"Sometimes I would feel like I could pull one over on them [clients] or I knew how to act to get it out of them and sometimes I'd think, man, I could rob you and what's your ass gonna do about it? -Deirdre

"I think about it like it [CSE] like it was part of the party and people wanted me."-Sierra

"When I'm on stage, I feel like I am in control. But that doesn't last." -Charity 
Challenges relating to structural disadvantage were also evident in the young women's narratives. Such challenges included circumvention of police surveillance because of undocumented status (Bella), gang involvement (Bella, Lucky), or other illegal activity in the home (Lucky, Charity, Sunshine), language barriers (Bella, Sierra), lack of adequate mental health services (Charity, Bella, Sierra), participation in the illicit economy (Sunshine, Charity, Deirdre, Lucky), and compromised supervision due to parents' working multiple jobs (Sierra, Bella) or taking care of multiple wards (Deirdre). Indeed, Lucky described how structure influenced her work opportunities: "It's not just that I have trouble finding work because I have a record. It's the way I look. When I applied for this one job as a janitor, I could tell what the guy saw. Gang tattoos... and you know, I'm Black, and I think that is what he's gonna see, what they see, a Black gang member. So it's hard getting away from it."

In addition to structural marginalization, troubled relationships, and the normalization of drugs, violence, and victimization in their everyday lives, involvement in other institutions - namely school, DHHS, and the justice system-were also problematic for the girls in this study. Despite a range of academic abilities, school was marginalizing for them. With the exception of Deirdre, whose earliest and consistent memories of school were of a place she "didn't belong," the girls in this study reported positive experiences in early elementary school-teachers appeared invested in them and cared about them, classmates were friends, and they had a certain ease in scholastic work:

"I was always good at school, I think. I liked reading, maybe 'cause I am kinda quiet so I could keep to myself with it."-Bella

"I don't have memories of hating school when I was little. I used to like going there because I remember this one teacher [name]. She was nice to me." Sunshine

"[Laughing]. I used to want to go to school. Yeah, like then I knew I was gonna get somethin' to eat."-Lucky

"When I was little, I remember school being a place where they'd care. Like... making sure we had Christmas presents and stuff." -Sierra

However, as they entered later grades, the multiple levels of disruption at home-especially constant moves, parents' arrests and incarceration, and DHHS placements - led to feelings of disconnection from peers and inadequacy in completing assignments. School became a source of strain, from worries about their home lives being exposed, to stress from changing schools and not knowing when and where they would attend, to difficulties in making new friends and finding time and space to complete assignments. Additionally, girls expressed concerns over seeming unkempt and consequent judgments from their classmates, as well as feeling too tired to pay attention in class.

"I worried how I looked... I felt other girls judging me."-Bella 
"You know, it's hard to sit there and try to, like, take a test or something when you haven't slept all night because of what is going on all the time, you know? No one seems to get that. Like hey: some of us got stuff going on!" -Lucky

"I was OK with school until I went back to living with my mom. I started...not wanting to go to school, sometimes because I knew it would make her mad but mostly I just didn't like it. I didn't really fit in anymore."-Sierra

Likewise, girls reported intervention by DHHS without "good" results, often feeling responsible when they were removed from their own, being exposed to assessments without meaningful follow-up treatment, or engaging in therapy they felt did not help. No interviewees could relate specifics about the counseling sessions they received, and none had records of receiving trauma-informed therapy through DHHS or through juvenile court or corrections. As Sierra explains, "When my dad first left, and part of going back to live with my mom was that I had to go to therapy with this woman who I felt didn't really care. She didn't speak Spanish, so my mom couldn't talk to her and it just seemed stupid. Like now, it seemed pointless."

Girls' reflections on their justice involvement rang similarly, especially in terms of the system's confusing and contradictory messaging between offender and victim. On the surface, girls were reluctant to plead responsible because they wanted to avoid consequences, punishment, and added surveillance to their lives. However, as girls were told they must "take responsibility for their choices" for offending behaviors, they were also told they were not responsible for their sexual victimization. When their victimization and exploitation connected to their offending (e.g., status offenses, drug use) or were part of their charges (e.g., prostitution), all interviewees expressed this awareness and consequent dissonance with their court involvement. They were resistant to accepting responsibility for their choices (especially for prostitution), as such choices were circumscribed by restriction, sense of inferiority, criticism, inflexibility, and lack of understanding. As Lucky explains, "Do you know how many times I have been told that no matter what I did, I do not deserve to be [sexually assaulted]? Or how many times I am not at fault for what someone else did to me? And yet, I am in court being told found responsible, found responsible, found responsible. Ridiculous." Bella also provided, "How can something be my fault when it is not my fault?" For some girls, their relationships with their probation officers were also puzzling for them, often being a difficult navigation between surveillance and care:

"My PO (probation officer) is great. She is one of my closest friends and took me to my ultrasound. But then when I tell her certain stuff, she's like, I could send you back to [detention] or maybe I should do a UA on you and then I'm like, wait, I thought you cared about me, not just looking to screw me up in some way." -Charity

"I like my PO but sometimes I feel like she's just waiting to get me on something... [with laughter] like a friend who can jack you up whenever they want and there ain't nothing you can do about it." -Sunshine 
"My PO is out to get me. He can be nice, but he doesn't like me. But I have had one who was OK, seemed to care." -Deirdre

“My PO...umm...another person to...I don't know....tell me how I'm wrong."-_Lucky

Overall, girls expressed frustration with the social and justice system involvement they experienced, ranging from feelings of ineffective intervention and constant judgment to lack of advocacy to role confusion with case managers and probation officers. Additionally, when probation officers were the ones responsible for doing group therapy and had no training or education with trauma-informed counseling, interviewees felt suspicious and defiant with such services. As Lucky described, "I think [PO] thought she was doing a good job with the group, but we would all sit there and be like, oh hell no, we ain't telling her shit." Girls expressed disinclination to embrace a "victim" label - a label all interviewees felt their participation in DHHS and court imprinted on them:

"If someone would have called me a victim when I was 8 or 9, I would have been OK with that if it came with some help for me and my mom. But now, I'm like, fuck you, I ain't no victim. Stop telling me that."-Charity

"And I really hate being called a victim. Especially when someone says that and talks about my dad. Like you don’t know my dad."--Sierra

"Who wants to be a victim? What does that get me? Doesn't get me out of trouble."--Sunshine

However, while that label made them feel weak and substandard, their participation in their outside relationships and environments consequently felt the same, with feelings of limitations in their power to decide and affect outcomes, consequences, and directions of their lives. Bella explains, "I don't think I ever make decisions for myself, not major ones anyway." However, their own court and correctional involvement were seen as solidifying their pathway of drug use, prostitution, and other criminality:

"I cannot imagine being without him." -Bella

“There's nothing else for me."-Deirdre

"I will never escape who I really am." -Charity

\section{Discussion-Running a Gauntlet}

An examination of the girls' life events, turning points, and reflections shows that the pathways approach to female offending, particularly among girls who have 
backgrounds of prostitution (CSE), can be a very useful tool for understanding how girls become involved with CSE. That said, this article has shown how the typologies and categories of previous pathways scholarship can be nuanced and enriched to more visibly demonstrate how extreme disadvantage and marginalization, childhood neglect and victimization, sexual abuse and assault, maternal abandonment, and involvement with informal and formal systems of control interact to produce and amplify girls' offending and strong enthrallment toward CSE. They also interact to produce and amplify girls' eroding sense of agency and power to change directions in their lives, essentially creating "a gauntlet" toward criminality and correctional supervision.

Building on previous pathways scholarship, this case study allows for the depth to explore the multiple (yet overlapping) distinctions offered by previously delineated typologies: childhood victimization, extreme marginalization, harmed and harming women, street woman, and anti-social aggressive women [7, 10, 34]. However, this case study suggests a greater emphasis needs to be placed on the challenges that confront their families and present as their major turns toward offending and CSE (poverty, racism, sexism, and resulting residential instability). These sources of strain produce a normalization of drug use and abuse as well as severe problems with family violence and early sexual abuse. For the girls growing up in these environments, the consequences are devastating and clearly linked to their ultimate involvement with CSE. Key here is the roles played by others in girls' choices, thus developing a punishing social world around them filled with powerlessness to change. Predictably, the girls point to problems with family members, especially mothers, which make them vulnerable to exploitative males. Their narratives, though, also show how child welfare workers, probation officers, and judges also contribute to girls becoming more, rather than less, embedded in criminality. That many of these individuals represent governmental systems involved in girls' lives because of their histories of abuse and behavior makes the criminogenic aspect of their involvements all the more troubling.

It is clear that these girls are growing up in families that are themselves deeply dysfunctional and unhealthy, displaying in some cases generational histories of sexual exploitation, violence, and drug abuse. Mothers, some of whom have themselves been involved in CSE, and others of whom are drug addicted and struggle with mental health issues, are unable to adequately protect their daughters, and are unavailable to them, which is a source of deep pain for the girls and a significant factor on their life courses to CSE and offending behaviors. The girls also show how their attachment to their mothers, when disrupted, served as a major turning point toward CSE and other forms of delinquency (truancy) and criminality (drugs). As Artz [2]) points out, familial patriarchal ideology supports the subjugation and violation of women, as it excuses or dismisses the violence of men. Girls in the case study often resonated such ideology, clinging to fathers and partners who were part of their initial experiences with violence, sexual assault, and/or exploitation, while blaming their mothers for being bystanders, if not collaborators, in such abuse.

The absence of non-exploitative male relationships is noteworthy in all these cases, as are the constant costs of poverty, including neglect, residential instability and/or homelessness, food insecurity, and fear of violence. As Deirdre pointed out, even places presumably for refuge and safety — such as shelters - become prime locations for pimps and CSE enthrallment. Because of traditional gender roles as well as the demands that result from economic marginalization and the lack of adequate social and drug 
treatment services, young girls also find themselves parentalized, often given outsized responsibility for the care of themselves and their siblings and often worrying about the safety and health of their mothers. As a result, girls were left without proper guardianship in dangerous home situations, and their neighborhoods were rife with economic strain, migrants who fear criminalization, gangs, and police detection.

These family dynamics, alone, are extremely destructive, and the results can be seen in the worldviews of these young women. They report few emotional attachments to other girls, loneliness, anger, drug abuse, and a strong attraction to exploitative men. Robbed of a conventional childhood, they report very limited feelings of safety or pleasure, except that which resulted from drug use or from occasional feelings of romantic attachment and sexual power. Their accounts are also devoid of much mention of extended family members, possibly reflecting the isolation created by maternal drug use and mental illness. Additionally, while some girls reported early positive school experiences, these tended to evaporate under the enormous pressure of dealing with family disruption. Recall Lucky saying, "You know, it's hard to sit there and try to, like, take a test or something when you haven't slept all night because of what is going on all the time."

Their victimization experiences, and efforts to avoid victimization (including runaway, gang involvement, and minor theft), often meant that they become increasingly detached from school and had no models of normal economic survival, let alone job training, which itself lies outside their zones of comfort and familiarity. Consequently, with emotional and social development marked by loneliness, fear, trauma, and percolating anger, they see little in their circumscribed world other than continued involvement with CSE.

Notable in their accounts is the specific role played by their early sexual victimization on their life trajectories (see [15]). Experiencing this abuse set many of these young women up for removal from their families and exposure to a child welfare system. By their accounts, this experience did not help them deal with the anger, depression, and isolation. Instead, contact with this system seems to have, in these cases, propelled them into criminal behavior, particularly CSE, as girls in this case study saw their system involvement as a turning point. Their remarks make it clear that child welfare systems lacked robust-and culturally aware-resources to help the young victims of family sexual and physical abuse, particularly the trauma associated with loss of the maternal bond (however flawed) as well as the trauma they have experienced associated with their abuse.

Involvement with the juvenile justice system was the outcome of their own survival strategies (which involve running away, using and possessing drugs, sometimes joining gangs, and prostituting) having been criminalized. That they began this journey as victims is an irony not lost on the girls. It is also one reason so many of them now reject the victim label. Recall Charity's clear assessment that "If someone would have called me a victim when I was 8 or 9 , I would have been OK with that if it came with some help for me and my mom. But now, I'm like, fuck you, I ain't no victim. Stop telling me that."

The girls reported numerous ways that the system, while noting their victimization histories, continued to blame them for their criminal choices, such as prostitution, and offered them few other alternatives, a situation one young women labeled as "ridiculous." Another said simply, "How can something be my fault when it is not my fault?" 
The girls also understood and resented the complicated and sometimes contradictory roles played by probation officers, as both counselors and officers of the court. Sunshine said her good relationship with her probation officer was still overshadowed by that complexity, "like a friend who can jack you up whenever they want and there ain't nothing you can do about it." More generally, they know they are in the system because their own efforts at survival, including CSE, have been criminalized. With personal power feeling limited and bodies repeatedly commoditized, their narratives share tones of feeling punished and attacked from all sides-family, school, DHHS, and juvenile court and corrections - hence, life running a gauntlet.

Moreover, feeling powerless to change did not translate into feeling like a victim. For several of the young women in this study, sex is viewed as their primary, if only, commodity and source of power. Linking low self-esteem to CSE, previous research on sex-trafficked women often fails to recognize how participation in the sex industry for these girls, however exploitative and possibly violent, can be viewed as positive by them, even if such interpretation is momentary. It makes sense then that these girls would feel resistant to frame such action and relationships as victimizing - it would dilute the positive association they have built. Sierra illustrated this point when she explained, "I think about it like it [CSE] was part of the party and people wanted me."

Looking forward, the girls have a heartbreaking, but clear eyed view of their futures. In particular, they all saw that their past criminal histories meant even the most modest aspirations were far beyond their reach, and that in many cases, they simply hoped to avoid future incarceration. Aware of such constrictions and unaware and untrained how to maximize choice and agency, the girls were hard-pressed to envision a different future, a sentiment that did not change throughout each interval of interviews.

\section{Conclusion and Policy Recommendations}

The pathways perspective to understanding sexually exploited female offenders is an important contribution in the field of feminist criminology and gender and crime, and further theoretical development and progress adds to our understanding of girls and women who find themselves in trouble with the law. Thinking about the girls' life histories and turning points as a developing "gauntlet" underscores the interconnection and intensity of pathways factors in CSE girls' lives and reveals the perceived constraint and challenges these young women express as they navigate their communities and households, approach relationships, think about their futures, and negotiate justice involvement. Understanding how they run a gauntlet in their everyday lives also allows room for development of more responsive programming because, as this article has shown, it is necessary to understand girls' lives before they enter correctional control, since they bring such problems with them into the institution (see [4], for example). Indeed, their problems are often "waiting for them" as they reenter, complicating parole survival and furthering recidivism and future imprisonment.

We understand that the girls profiled in this particular case study represent only a portion of all young women who find themselves in the justice system. We also 
recognize that the small number of cases reported here is a limitation of this research, and we hope that further research on larger samples of CSE girls and young women can add to this analysis and development of the pathways perspective. Indeed, research that centers more in-depth and thoroughly on agenic change and desistance performed by young women of similar narratives and histories would be beneficial both in theory and for programming. There exists a paucity of such research when it clearly is vital, since the lives of these young girls contradict previous understandings of CSE and do not remotely resemble some of the more simplistic constructions of "sex trafficked girls" who are often described as having been duped by sophisticated pimps in shopping malls and bear virtually no relationship to the lives understood in this case study. Moreover, this construction misdirects those working with CSE youth away from genuine threats in the lives of these young women.

What emerges from this study is an evident policy implication, at least in the USA. Schools and other welfare and health service systems are in need of revision and repair in order to adequately address CSE girls' lives and needs, especially in terms of recognizing risks and offering trauma-informed care. We recognize that this, too, is a somewhat case study-specific recommendation. In other jurisdictions and international locations, programming for girls wishing to exit prostitution and trauma-informed approaches is indeed actualized or in development to do so [24]. In the USA, however, many districts remain focused on identifying and punishing delinquent girls, and recommendations often refuse to address the problems of these multiple failing systems. The content of gender-specific (or girl-sensitive) programs formed within the juvenile justice system requires special attention, since the family court has a long history of paternalism and policing of girls' sexuality without sensitive, nuanced, girl-centered approaches [8]. Programming for this population often fails to offer girls spaces, experiences, and relationships that will move them past CSE. While not apologizing for them or reducing them to victims of life circumstances, programming must be trauma-informed and address the obstacles that are presented by girls' perceptions of judgment and powerlessness associated with the prostitute, offender, and victim designations, as well as the emotional familiarity, attachment, and comfort that comes with a return to CSE relationships and environments. Without awareness or sensitivity to these perceptions, girls may show reluctance to engage in the court's or program's efforts.

Additionally, a primary contribution of this article is illustrating how important mothers are in the CSE pathways of their daughters, either directly or indirectly, and as such, this must be addressed and incorporated into programming efforts. Lastly, without recognizing the intensity of violence and marginalization as well as the multiple levels of enthrallment surrounding sexual exploitation, presenting girls with basic life skills and vocational and/or educational opportunities may not be enough. While such components are necessary, program development and its implementation need to acknowledge the gauntlet girls run during their everyday lives, to dismantle the effects of the victim/offender label; to assist girls in their development of new types of enthrallment in their lives; to acknowledge their needs for healthy emotional attachment, romance, affection, and care; and to offer a diversity of choices; and to recognize and amplify girls' perceived openings for change and resiliency. 


\section{References}

1. Acoca, L. (1998). Outside/Inside: the violation of American girls at home, in the streets, and in the system. Crime and Delinquency, 44, 561-590.

2. Artz, S. (1997). Sex, power, and the violent school girl. New York: Teachers College Press.

3. Bailey, J., \& McCloskey, L. (2005). Pathways to adolescent substance use among sexually abused girls. Journal of Abnormal Child Psychology, 33, 39-54.

4. Belknap, J. (2014). The invisible woman (4th ed.). Belmont: Wadsworth.

5. Bergen, H., Martin, G., Richardson, A., Allison, S., \& Roeger, L. (2004). Sexual abuse, antisocial behaviour and substance use: gender differences in young community adolescents. Australian and New Zealand Journal of Psychiatry, 38, $34-41$.

6. Bloom, B., Owen, B., Deschenes, E. P., \& Rosenbaum, J. (2002). Improving juvenile justice for females: a statewide assessment for California. Crime and Delinquency, 48, 526-552.

7. Brennan, T., Breitennach, M., Dieterich, W., Salisbury, E. J., \& Van Voorhis, P. (2012). Women's pathways to serious and habitual crime: a person-centered analysis incorporating gender responsive factors. Criminal Justice and Behavior, 39, 1481-1508.

8. Chesney-Lind, M., \& Pasko, L. (2013). The female offender: girls, women, and crime (3rd ed.). Thousand Oaks: Sage.

9. Chesney-Lind, M., \& Sheldon, R. (2014). Girls, delinquency, and juvenile justice (3rd ed.). Belmont: Wadsworth.

10. Daly, K. (1992). Women's pathways to felony court: feminist theories of lawbreaking and problems of representation. Rev Law Women's Studies, 2, 11-52.

11. Dorais, M., \& Carriveau, P. (2009). Gangs and girls: understanding juvenile prostitution. Montreal: McGill-Queen's University Press.

12. Dunlap, E., Golub, A., Johnson, B., \& Wesley, D. (2002). Intergenerational transmission of conduct norms for drugs, sexual exploitation, and violence: a case study. British Journal of Criminology, 42, 1-20.

13. Erez, E., \& Berko, A. (2010). Pathways of Arab/ Palestinian women in Israel to crime and imprisonment: an intersectional approach. Feminist Criminology, 10, 156-194.

14. Farley, M., \& Kelly, V. (2008). Prostitution: a critical review of the medical and social sciences literature. Women \& Criminal Justice, 11(4), 29-64.

15. Finkelhor, D., \& Browne, A. (1985). The traumatic impact of child sexual abuse: a conceptualization. American Journal of Orthopsychiatry, 55, 530-541.

16. Gaarder, E., \& Belknap, J. (2002). Tenuous borders: girls transferred to adult court. Criminology, 40, 481-517.

17. Gillespie, C. (1990). Justifiable homicide: battered women, self-defense, and the law. Columbus: Ohio University Press.

18. Holger-Ambrose, B., Langmade, C., Edinburgh, L., \& Saewyc, E. (2013). The illusions and juxtapositions of commercial sexual exploitation among youth: identifying effective street-outreach Strategies. Journal of Child Sexual Abuse, 22, 326-340.

19. Huebner, B., DeJong, C., \& Cobbina, J. (2010). Women coming home: Long-term patterns of recidivism. Justice Quarterly, 27, 225-254.

20. Jacobs, J. (1993). Victimized daughters: Sexual violence and the empathic self. Signs, 19, 126-146.

21. Johansson, P., \& Kempf-Leonard, K. (2009). A gender-specific pathway to serious, violent, and chronic offending? Exploring Howell's risk factors for serious delinquency. Crime \& Delinquency, 55(2), 216-240.

22. Jones, N., Brown, S., Wanamaker, K., \& Greiner, L. (2014). A quantitative exploration of gendered pathways to crime in a sample of male and female juvenile offenders. Feminist Criminology, 9(2), 113-136.

23. Leve, L., \& Chamberlain, P. (2004). Female juvenile offenders: defining an early-onset pathway for delinquency. Journal of Child and Family Studies, 13, 439-452.

24. Lloyd, R. (2012). Girls like us. New York: Harper.

25. McCabe, K. M., Lansing, A. E., Garland, A., \& Hough, R. (2002). Gender differences in psychopathology, functional impairment, and familial risk factors among adjudicated delinquents. Journal of the American Academy of Child and Adolescent Psychiatry, 47, 860-868.

26. McCartan, L., \& Gunnison, E. (2010). Individual and relationship factors that differentiate female offenders with and without a sexual abuse history. Journal of Interpersonal Violence, 25(8), 1449-1469.

27. Mellin, E., \& Fang, H. H. (2010). Exploration of the pathways to delinquency for female adolescents. Journal of Addictions \& Offender Counseling, 30(2), 58-72. 
28. Messerschmidt, J. (1999). Nine lives: masculinities, the body, and violence. New York: Westview Press.

29. Mullis, R. L., Cornille, T., Mullis, A., \& Huber, J. (2004). Female juvenile offending: a review of characteristics and contents. Journal of Child and Family Studies, 13, 205-218.

30. National Center for Missing and Exploited Children. (2015). Missing children, state care, and child sex trafficking. Washington, DC: National Center for Missing and Exploited Children.

31. Pasko, L. (2010). Damaged daughters: The history of girls' sexuality and the juvenile justice system. Journal of Criminal Law and Criminology, 100 (3), 1099-1130.

32. Reid, J., \& Piquero, A. (2014). On the relationships between commercial sexual exploitation/prostitution, substance dependency, and delinquency in youthful offenders. Child Maltreatment, 19(3-4), 247-260.

33. Reinharz, S. (1992). Feminist methods in social research. Oxford: Oxford University Press.

34. Richie, B. E. (1996). Compelled to crime: the gender entrapment of black battered women. New York: Routledge.

35. Richie, B. (2001). Challenges incarcerated women face as they return to their communities: Findings from life history interviews. Crime \& Delinquency, 47, 368-389.

36. Rodney, H., \& Mupier, R. (2004). The special needs of girls in trouble. Reclaiming Children and Youth, 13, 103-109.

37. Salisbury, E., \& van Voohis, P. (2009). Gendered pathways: a quantitative investigation of women's pathways to incarceration. Criminal Justice \& Behavior, 36, 541-566.

38. Schaffner, L. (2007). Violence against girls provokes girls' violence: from private injury to public harm. Violence against Women, 13, 1229-1248.

39. Sewell, W. (1992). A theory of structure: duality, agency, and transformation. American Journal of Sociology, 98, 1-29.

40. Shechory, M., Perry, G., \& Addad, M. (2011). Pathways to women's crime: Differences among women convicted of drug, violence and fraud offenses. The Journal of Social Psychology, 151, 399-416.

41. Simkins, S., \& Katz, R. (2002). Criminalizing abused girls. Violence against Women, 8, 1474-1500.

42. Somers, C. L., \& Gizzi, T. L. (2001). Predicting adolescents' risky behaviors: the influence of future orientation, school involvement, and school attachment. Adolescent and Family Health, 2, 3-11.

43. Turner, T., \& Tofler, D. (1986). Indicators of psychiatric disorder in women admitted to prison. British Medical Journal, 292, 651-653.

44. Ullman, S. (2004). Sexual assault victimization and suicidal behavior in women: a review of the literature. Aggression and Violent Behavior, 9, 331-351.

45. Wattanaporn, K., \& Holtfreter, K. (2014). The impact of feminist pathways research on gender-responsive policy and practice. Feminist Criminology, 9, 191-207.

46. Williams, L., \& Frederick, M. (2009). Pathways into and out of commercial sexual victimization of children: understanding and responding to sexually exploited teens. Washington, DC: Fairfund, Inc.

47. Wilson, H. W., \& Widom, C. S. (2010). The role of youth problem behaviors in the path from child abuse and neglect to prostitution: a prospective examination. Journal of Research on Adolescence, 20, 210-236.

48. Wilson, B., \& Butler, L. (2014). Running a gauntlet: a review of victimization and violence in the preentry, post-entry, and peri-/post-exit periods of commercial sexual exploitation. Psychological Trauma: Theory, Research, Practice, and Policy, 6, 494-504. 